\title{
Development of an inductively coupled power transfer system (ICPT) for electric vehicles with a large airgap
}

\author{
J.L.Villa, A. Llombart, J.F.Sanz, J.Sallan \\ Electric Engineering Department, University of Zaragoza \\ C/María de Luna 3, 50018, Zaragoza, Spain. \\ CIRCE Foundation. University of Zaragoza. C/María de Luna 3, 50018, Zaragoza, Spain \\ jvilla@unizar.es, llombart@unizar,jfsanz@unizar.es, jsallan@unizar.es,
}

\begin{abstract}
An Inductively Coupled Power Transfer system (ICPT) of $5 \mathrm{~kW}$ that allows an air gap of $20 \mathrm{~cm}$ has been studied and developed. The mechanical scheme is shown in Fig. 1. The study has been focused in analyzing the influence of the frequency deviation with respect to the resonant frequency. This study has been carried out as a part in the development of a supply system for electric vehicles both with still and moving secondary. This paper shows the analysis process followed, the practice process carried out to build the prototype and the conclusions of the work.
\end{abstract}

\section{Keywords}

Inductively coupled Power transfer (ICPT), energy conversion, Contact-less energy transfer, electromagnetic coupling, electric vehicles

\section{Introduction}

In many applications, inductively coupled power transfer (ICPT) systems have several advantages over conventional energy transmission using wires and connectors. For example, ICPT has been the preferred system in hazardous applications due to the elimination of the sparkling and the risk of electrical shocks [1]. The development of such systems is improving and the numbers of applications where they are suitable grow step by step: contact-less power supply for professional tools [2], contact-less battery charging across large air gaps for electric vehicles [3], compact electronic devices [4], mobile phones [5], public transport systems [6]...

Generally, an ICPT is implemented by using magnetic induction, i.e., by employing specially constructed transformers. In such transformers, the energy from the primary to the secondary is transferred inductively through the air. It is quite common that ICPT have a relatively large separation between the primary and secondary winding. Therefore, the characteristics of these transformers are very different from those of conventional transformers that have good coupling between the windings.

Due to a large winding separation, ICPT systems have a relatively large leakage inductance, as well as increased proximity-effect winding losses. Furthermore, for the ICPT where the primary and secondary winding are separated by an air gap, the magnetizing significantly reduced. This fact implies the need of greater magnetizing current and greater leakage inductances.

All these features make the power factor to be low in both the primary and secondary side reducing significantly the efficiency of the system. To improve the behaviours of ICPT several studies have been carried out in order to study the best way of power factor compensation. In $[7,8]$ different compensation schemes are proposed and their benefits are presented. In spite of these studies the design procedure of ICPT is not clear. In [9] a procedure to do so is presented but there still remain many design decisions that depend on the actual case which implies that the design procedure requires the development of three steps:

$>$ Getting the minimum requirements (i.e. voltage on both sides, power...)

$>$ Performing a first theoretical study

$>$ Simulating the approach

$>$ Testing experimentally the final approach

The different developed studies consider as a high distance between primary and secondary side something like $5 \mathrm{~cm}$. We consider that for public transport this may be low. So, to cover these questions, this paper studied a $5 \mathrm{~kW}$ ICPT system with an air gap of $20 \mathrm{~cm}$.

The system was designed to deliver power efficiently from a stationary primary source to one or more movable secondary loads over relatively large air gaps via magnetic coupling. 


\section{ICPT theoretical model}

A. Power transfer capability

The power transfer capability of an ICPT system depends directly on the coupling coefficient [1] which is given by

$$
\mathrm{k}=\frac{\mathrm{M}}{\sqrt{\mathrm{L}_{1} \mathrm{~L}_{2}}}
$$

where subscripts " 1 " and " 2 " stand for primary and secondary windings.

If an SS compensation is selected, the primary capacitance is independent of either the magnetic coupling or the load [9]. The power transferred from the primary to the secondary is given by

$$
\mathrm{P}_{2}=\frac{\omega_{0}{ }^{2} \mathrm{M}^{2}}{\mathrm{R}_{\mathrm{L}}} \mathrm{I}_{1}{ }^{2}
$$

Where " $\omega_{0}$ " is the resonant frequency of the primary and secondary and is normally chosen [9]

$$
\omega_{0}=\frac{1}{\sqrt{\mathrm{L}_{1} \mathrm{C}_{1}}}=\frac{1}{\sqrt{\mathrm{L}_{2} \mathrm{C}_{2}}}
$$

\section{B. Equivalent Circuit Parameters}

To obtain the theoretical values of $L_{1}, L_{2} y$ the following expressions must be used.

$\mathrm{L}_{1}$ is given by:

$$
\begin{aligned}
& L_{1}=\frac{\mu_{0}}{\pi} N_{1}^{2}\left[d \cdot \ln \frac{2 L d}{R_{1}\left(d+\sqrt{L^{2}+d^{2}}\right)}\right] \\
& +\frac{\mu_{0}}{\pi} N_{1}^{2}\left[L \cdot \ln \frac{2 L d}{R_{1}\left(L+\sqrt{L^{2}+d^{2}}\right)}-2\left(d+L-\sqrt{d^{2}+L^{2}}\right)\right] \\
& +\frac{\mu_{0}}{4 \pi} N_{1}^{2}(L+d)
\end{aligned}
$$

and $\mathrm{L}_{2}$ is given by

$$
\begin{aligned}
& L_{2}=\frac{\mu_{0}}{\pi} N_{2}^{2}\left[d \cdot \ln \frac{2 a d}{R_{2}\left(d+\sqrt{a^{2}+d^{2}}\right)}\right] \\
& +\frac{\mu_{0}}{\pi} N_{2}^{2}\left[a \cdot \ln \frac{2 a d}{R_{2}\left(a+\sqrt{a^{2}+d^{2}}\right)}-2\left(d+a-\sqrt{d^{2}+a^{2}}\right)\right] \\
& +\frac{\mu_{0}}{4 \pi} N_{2}^{2}(a+d)
\end{aligned}
$$

where $R_{1}$ and $R_{2}$ are the equivalent radius of the windings

$$
R_{1}=\sqrt{\frac{N_{1} S_{1}}{\pi}} ; R_{2}=\sqrt{\frac{N_{2} S_{2}}{\pi}}
$$

And the mutual inductance coefficient $\mathrm{M}$ when the two coils have the same dimensions is given by

$$
\begin{aligned}
& M=\frac{\mu_{0}}{\pi} N_{1} N_{2}\left[d \ln \left(\frac{d+\left(\sqrt{h^{2}+d^{2}}\right)\left(\sqrt{h^{2}+a^{2}}\right)}{d+h \sqrt{h^{2}+d^{2}+a^{2}}}\right]+\right. \\
& \frac{\mu_{0}}{\pi} N_{1} N_{2}\left[a \ln \left(\frac{a+\left(\sqrt{h^{2}+d^{2}}\right)\left(\sqrt{h^{2}+a^{2}}\right)}{a+h \sqrt{h^{2}+d^{2}+a^{2}}}\right]+\right. \\
& \frac{\mu_{0}}{\pi} N_{1} N_{2}\left[2\left(h-\sqrt{h^{2}+d^{2}}-\sqrt{h^{2}+a^{2}}+\sqrt{h^{2}+d^{2}+a^{2}}\right)\right]
\end{aligned}
$$

Considering a case where the primary track is longer than the secondary pick up, $\mathrm{L}>>\mathrm{a}$; the mutual inductance can be approximated by

$$
M=\frac{\mu_{0}}{\pi} N_{1} N_{2} a \ln \left[\frac{\sqrt{h^{2}+d^{2}}}{h}\right]
$$

The resistive values of the windings can be calculated by

$$
\begin{aligned}
& R_{1}=\frac{1}{57} N_{1} \frac{2(L+d)}{S_{1}} \\
& R_{2}=\frac{1}{57} N_{2} \frac{2(a+d)}{S_{2}}
\end{aligned}
$$

\section{Operational Frecuency}

Working at secondary resonance frequency, the efficiency of the system is given by 


$$
\eta=\frac{R_{L}}{R_{L}+R_{2}} \frac{1}{1+\frac{R_{1}\left(R_{L}+R_{2}\right)}{\omega_{r} M^{2}}}
$$

In order to achieve maximum efficiency

$$
f_{r}>>\frac{\sqrt{R_{1}\left(R_{L}+R_{2}\right)}}{2 \pi M}
$$

As can be seen in (12) the better the coupling between the two coils, the lower the design frequency.

Capacitors $\mathrm{C}_{1}$ and $\mathrm{C}_{2}$ must be selected at the secondary resonant frequency [2] in order to achieve maximum power transfer capability.

$$
\begin{aligned}
& C_{2}=\frac{1}{\omega_{r} L_{2}} \\
& C_{1}=\frac{1}{\omega_{r} L_{1}}
\end{aligned}
$$

\section{Prototype design}

The initial parameters of the prototype were thought taking into account a transport application, where a moving pickup takes energy from a stationary track.

The air gap value was set to $20 \mathrm{~cm}$ in order to avoid mechanical problems, and the dimensions are shown in fig. 1. The electric specifications in the load were $\mathrm{P}_{2}=5 \mathrm{~kW}$, $\mathrm{V}_{2}=60 \mathrm{~V}$. The power was fixed by the application and the voltage thinking in a battery set composed of four $12 \mathrm{~V}$ elements. Set power and voltage, the equivalent $\mathrm{R}$ load is $0.7287 \Omega$, and the secondary current $\mathrm{I}_{2}=83.3 \mathrm{~A}$.

Once the parameters related to the application of the ICPT system were chosen, the first issue was calculating other parameters like the number of coils in each winding, the resonant frequency and the compensation capacitors.

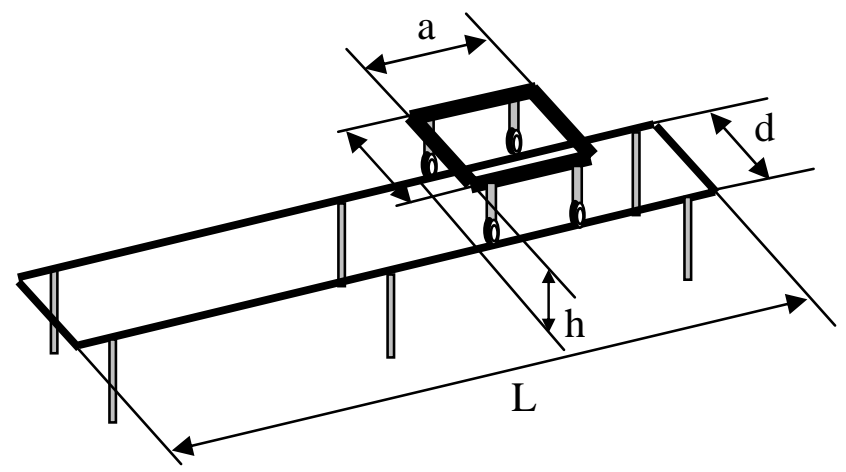

$\mathrm{d}=0.87 \mathrm{~m} ; \mathrm{N} 1=7 ; \mathrm{N2}=7 ; \mathrm{h}=0.2 \mathrm{~m} ; \mathrm{L}=4 \mathrm{~m} ; \mathrm{a}=1.2 \mathrm{~m} ; \mathrm{s} 1=10 \mathrm{e}-6 \mathrm{~mm} 2 ; \mathrm{s} 2=30 \mathrm{e}-$ $6 \mathrm{~mm} 2$.

Fig.1. Schematic of the model implemented and design parameters.
The different equations that define the ICPT system behavior as shown in section II where implemented in a Matlab program.

This model calculates the resonant frequency, the capacitors $\mathrm{C}_{1}$ and $\mathrm{C}_{2}$, the voltages across the capacitors $V_{C 1}, V_{C 2}$, the primary power $P_{1}$, the power of the load $P_{2}$, the primary and secondary currents $\mathrm{I}_{1}$ and $\mathrm{I}_{2}$ and the efficiency $(\eta)$.

An optimization process was carried out in order to find the parameters that optimize the efficiency minimizing the voltage across the resonant capacitors. The initial values obtained in the simulation are given in table I-a and the equivalent circuit is shown in Fig 2.

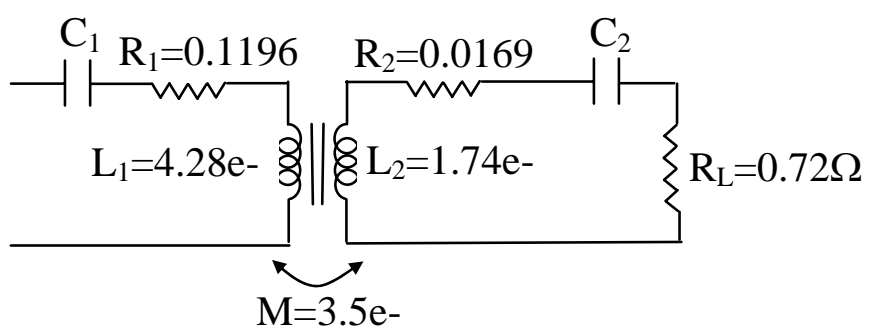

Fig.2. Scheme of the implemented model and theoretical parameters.

The obtained number of coils was 7 in both sides, and the sections of the windings were to $S_{1}=10 \mathrm{~mm}^{2}$ and $S_{2}=30$ $\mathrm{mm}^{2}$. In the aforementioned expressions it is not considered that the working frequency is high, so the real resistance values will differ from the calculated ones.

TABLE I.-Theoretical values of the matlab model versus real values and mounted values

\begin{tabular}{|l|c|c|c|}
\hline & a) Theoretical & b) Practical & c) Mounted \\
\hline $\mathrm{f}_{\mathrm{r}}$ & $1.5941 \mathrm{e}+004 \mathrm{~Hz}$ & $15.6 \mathrm{kHz}$ & $14.9 \mathrm{kHz}$ \\
\hline $\mathrm{k}$ & 0.1288 & 0.137 & 0.137 \\
\hline $\mathrm{C} 1$ & $2.3257 \mathrm{e}-7 \mathrm{~F}$ & $2.325 \mathrm{e}-7 \mathrm{~F}$ & $2.2 \mathrm{e}-7$ \\
\hline $\mathrm{C} 2$ & $5.7222 \mathrm{e}-7 \mathrm{~F}$ & $7.224 \mathrm{e}-7 \mathrm{~F}$ & $7.8 \mathrm{e}-7$ \\
\hline $\mathrm{I} 1$ & $17.92 \mathrm{~A}$ & $18.78 \mathrm{~A}$ & $19.88 \mathrm{~A}$ \\
\hline $\mathrm{I} 2$ & $83 \mathrm{~A}$ & $83.35 \mathrm{~A}$ & $82.08 \mathrm{~A}$ \\
\hline VC1 & $755 \mathrm{~V}$ & $823.6 \mathrm{~V}$ & $963.2 \mathrm{~V}$ \\
\hline VC2 & $1443 \mathrm{~V}$ & $1177 \mathrm{~V}$ & $1124 \mathrm{~V}$ \\
\hline VL & $60.2 \mathrm{~V}$ & $60.2 \mathrm{~V}$ & 59.6 \\
\hline P1 & $5150 \mathrm{~W}$. & $5325 \mathrm{~W}$ & 5445 \\
\hline P2 & $4981 \mathrm{~W}$. & $5002 \mathrm{~W}$ & 4891 \\
\hline$\eta$ & $96.7 \%$ & $93.9 \%$ & $89.8 \%$ \\
\hline
\end{tabular}

\section{Practical implementation}

A contact-less ICPT system battery charging with the dimensions of fig.1, has been designed in order to validate the theoretical results, as shown in fig. 3. The coils were wound using Litz wire to minimize the resistive losses at high frequency. 


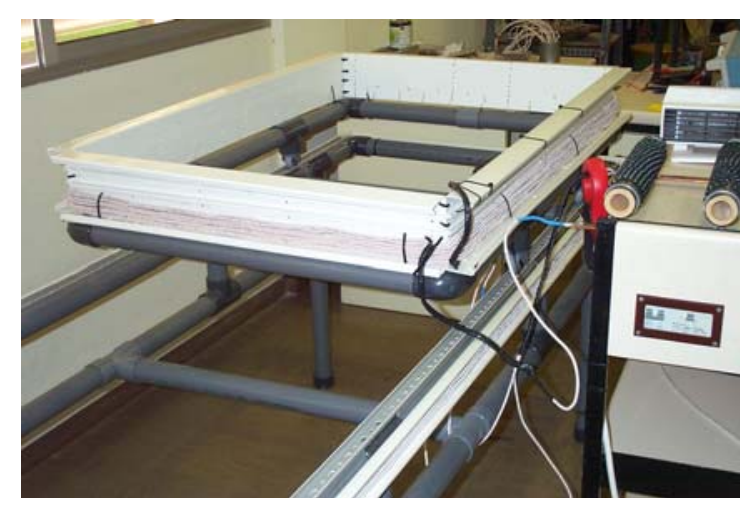

Fig.3. Practical implementation of the proposed system with the long primary track and the pick up.

First, when the two coils were mounted, $\mathrm{R}_{1}, \mathrm{R}_{2}, \mathrm{~L}_{1}$ and $\mathrm{L}_{2}$ were measured at $15.6 \mathrm{kHz}$ and the results can be seen in Table II-b

TABLE II.- Theoretical values of matlab model Versus real values

\begin{tabular}{|l|c|c|}
\hline & a) Theoretical & b) Practical \\
\hline R1 & $0.12 \Omega$ & $0.26 \Omega$ \\
\hline R2 & $0.017 \Omega$ & $0.042 \Omega$ \\
\hline L1 & $4.28 \mathrm{e}-4 \mathrm{H}$ & $4.48 \mathrm{e}-4 \mathrm{H}$ \\
\hline L2 & $1.74 \mathrm{e}-4 \mathrm{H}$ & $1.44 \mathrm{e}-4 \mathrm{H}$ \\
\hline
\end{tabular}

The inductance values obtained from the Matlab model were very close to the real values of the implemented prototype, but the resistances were higher because the values in (9) and (10) were calculated in DC, without taking into account the influence of the high frequency.

With these news values, the parameters of the Matlab model were recalculated and are shown in Table I-b.

The next step in the design was finding the capacitors. It was very difficult to find exactly the required capacitance, so the values were aproximated. C1 consisted of four 0.22 $\mu \mathrm{F}, 1000 \mathrm{~V}$ capacitors; C2 consisted of fifteen $0.47 \mu \mathrm{F}$, 1000V capacitors (Fig.4)

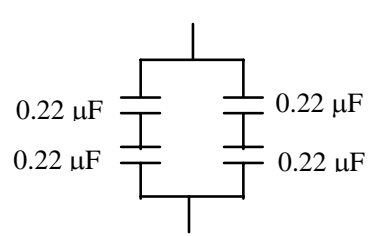

$\mathrm{C} 1=0.22 \mu \mathrm{F}$

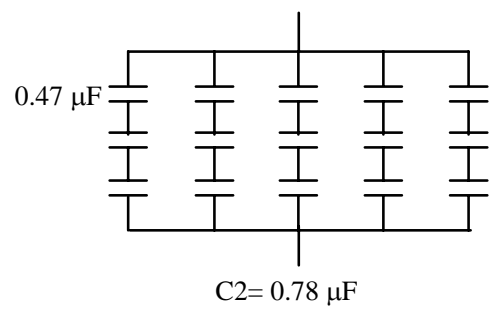

$$
\mathrm{C} 2=0.78 \mu \mathrm{F}
$$

Fig.4. Scheme of the capacitor sets

With these definitive capacitors, the resonant frequency was $14.9 \mathrm{kHz}$ and the results obtained with the Matlab model are given in Table I-c.

\section{Experimental Results}

The primary coil is fed with a square wave voltage from a full bridge inverter [4] with PWM control. The voltage $\mathrm{V}_{1}$ is controlled by the Duty Cycle (DC). The control schematic is shown in Fig. 4

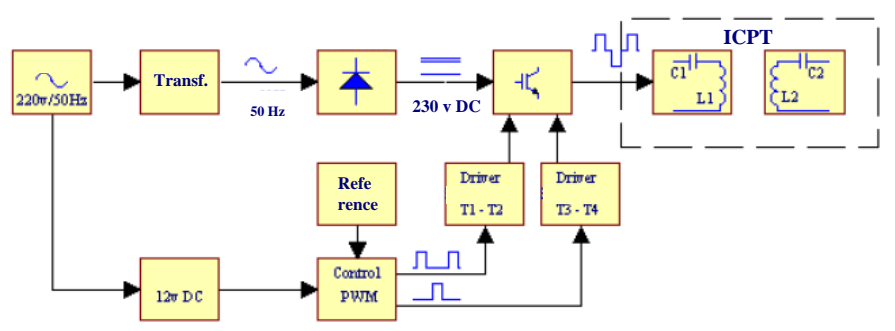

Fig.5. Block diagram of the PWM control for the proposed system.

A PWM control was needed to avoid the transitory of the current (fig.6). When the voltage is applied directly from the source, the current has a transitory about $3 \mathrm{~ms}$ and the peak primary current is about 2.5 times the peak in steady state
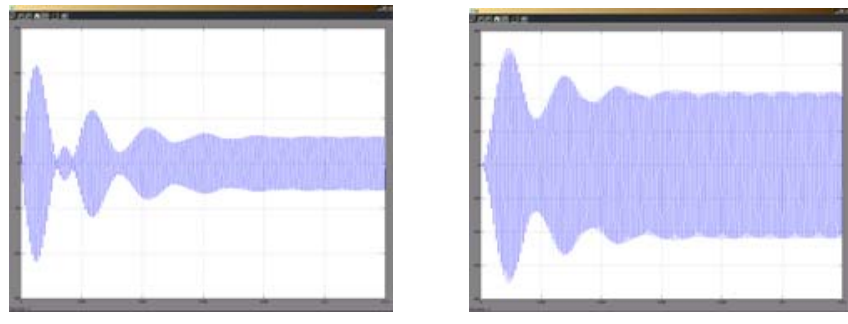

Fig.6. Transitory of currents I1 and I2 with DC=1

The first test was to check the frequency of optimum efficiency in the implemented prototype, in order to validate the model; and it was determinate at $\mathrm{fr}=14.55 \mathrm{kHz}$ as shown in Fig.7. This frequency is very closed to the calculated theoretical resonant frequency, so the mathematical model is validated to design the ICPT. Beside, the real efficiency was $88.4 \%$ instead of the expected $89.8 \%$

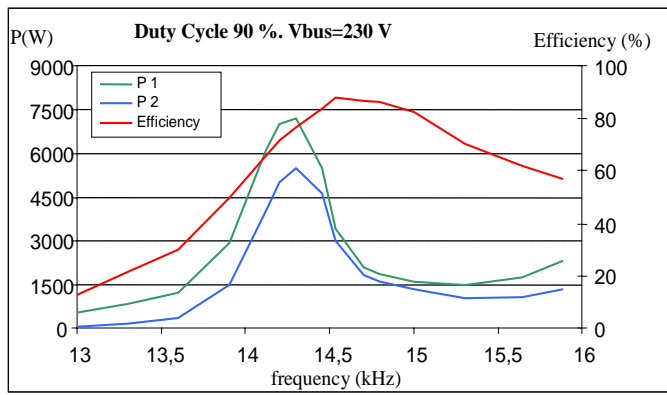

Fig.7. Frequency of maximum efficiency 
It is necessary to control the frequency of the primary to work always at maximum efficiency,[9],[10].

The second test was to see the influence in the efficiency of the system at the resonant frequency varying the Duty Cycle, in order to check the influence when the ICPT is fed with a non sinusoidal voltage wave form as shown in Fig. 8. It was verified that the efficiency is dependent on the Duty Cycle, because the current is less sinusoidal whith low DC ratio.

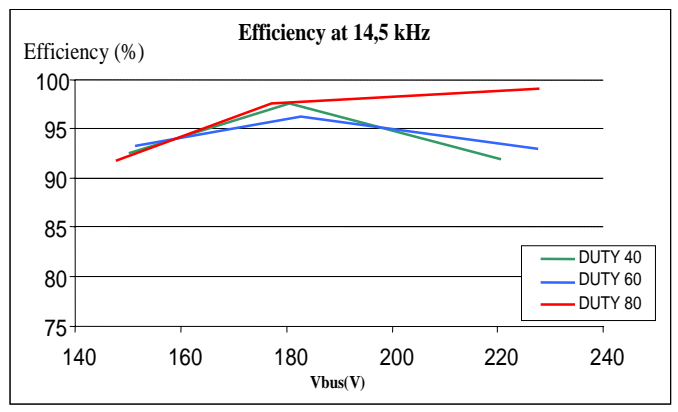

Fig.8. Variation of the efficiency at resonant frequency when DC change

\section{Conclusion}

The theory of ICPT is well known, but in practice it is difficult to determine the parameters of the coils and the resonant frequency. Moreover, this frequency depends strongly on parameters such as the distance between coils, the load, the shape of the current, etc, so a good control is obligatory in order to maintain the stability of the system. This paper shows the practical implementation of an ICPT with a large air gap and shows how these parameters affect the normal operation.

A $5 \mathrm{~kW}$ ICPT prototype has been developed in order to verification the theoretical results and the system's efficiency when the primary coil is fed with a square wave voltage from a full bridge inverter [4]. Besides that, the stability of the system and the possibility of power transfer when deviations of frequency. The results are used to design a system to achieve maximum power transfer and stability.
Different test have been carried out in order to check the correct operation of the system and they have shown that a high efficiency, up to 95\%, can be achieved even with a large air gap of $20 \mathrm{~cm}$.

\section{References}

[1] D.A.G. Pedder, A. D. Brown and J. A. Skinner, "A contactless electrical energy transmission system”, IEEE trans. on Industrial Electronics, vol. 46, pp 2330, feb. 1999

[2] T. Bieler, M. Perrotter, V. Nguyen and Y. Perriard, "Contactless power and information transmission" Conf. Rec. IEEE-IAS Annual Meeting, vol. 1, pp. 8388, 2001.

[3] R. Laouner, M. Brunello, J. P. Ferrieux, O. Normand and N.Buchheit, "A multi-resonant converter for noncontact charging with electromagnetic coupling" Pro. IEEE IECON'97, vol. 2 pp. 792-797, 1997

[4] H. Abe, H. Sakamoto and K. Harada, "A noncontact charger using a resonant converter with parallel capacitor of the secondary coil", IEEE trans. on Industrial Applications, vol. 36, $\mathrm{N}^{\circ}$ 2, pp. 444-451, 2000.

[5] Y. Jang and M. Jovanovic, “A contactless electrical energy transmission system for portable-telephone battery chargers", Telecommunications Energy conference, pp. 726-732, 2000

[6] G. A. Covic, G. Elliot, O. H. Stielay, R. M. Green and J. T. Boys, "The design of a contactless energy transfer system for a people mover system", International Conference on Power System Technology, vol. 1 pp. 79-84, 2000

[7] Chwei-Sen Wang, G.A.Covic and O.H. Stielau, "Power Transfer Capability and Bifurcation Phenomena of Loosely Coupled Inductive Power Transfer System” IEEE Trans. On Industrial Electronics, vol. 51, no. 1, pp 148-157, February 2004

[8] Chwei-Sen Wang, Grant A. Covic and Oskar H. Stielau, "Investigating an LCL Load Resonant Inverter for Inductive Power Transfer Applications”, IEEE Trans. On Industrial Electronics, vol. 19, no. 4, pp 995-1001, July 2004

[9] Chwei-Sen Wang, Oskar H. Stielau, and Grant A. Covic, "Desing Consideration for a Contactless Electric Vehicle Battery Charger" IEEE Trans. On Industrial Electronics, vol. 52, no. 5, pp 1308-1313, October

[10] Aiguo Patrick Hu, Stephan Hussman, “ Improved Power Flow Control for Contactless Movig Sensor Applications"; IEEE Power Electronics Letters, vol.2, no .4, pp 135-138 